\title{
Some of the Impact of Mediatisation of Mediation Law Process
}

\author{
Av. Eni Cobani \\ Lawyer, \\ Lecturer at University of Tirana, Albania \\ Dr. Engjëllushe Zenelaj \\ Director, Research Center on Human Sciences \\ University College "Pavaresia Vlore", Albania
}

Doi: 10.2478/ajis-2018-0053

\begin{abstract}
The mediation process is a relatively new form in the legal treatment of legal disputes in Albania. The mediation process is the forerunner of solving a conflict between the parties, and unites them for a unanimous request to the court. The media as the fourth power plays a powerful role in addressing many social and state processes. The role of the media in the overall development of society has already been highlighted, and today in the era of information technology, of course, the media for such delicate issues plays a huge role. The purpose of the article is to highlight the role of media treatment or mediatisation of the mediation process as well as the analysis of the consequences of this process. Mediated cases mediated in the media are accompanied by various reactions, both from the official side of the institutions, which are directly or indirectly affected, but also from the public opinion. Like the nature of legal conflicts, social conflicts are also endless. Often legal complications are even worse because of disagreements between individuals, even when they pursue the same goal.
\end{abstract}

Keywords: mediation, law, media, social impact, conflict, moderator

\section{Mediation as Legal Act}

Mediation law refers to a form of alternative dispute resolution (ADR) in which the parties to a lawsuit meet with a neutral third-party in an effort to settle the case. The third-party is called a mediator (mediation-definition, 1995). Mediation is a form of dispute resolution, found outside the adjudicative space of the court-room or tribunal, where parties in dispute or conflict utilize the assistance of a third party neutral to attempt to resolve their dispute. It is different from other forms of alternative dispute resolution- such as negotiation, conciliation, arbitration, and early neutral evaluation- in that the third party neutral, the mediator is present and assigned a number of qualities that are not as evident or strictly adhered to, in the other forms of dispute resolution (Spencer, D., Brogan, M, 2006) .

The mediation process is represented as unrelated to any legal logic, merely intended to highlight and bring together interests, desires, and values that have nothing to do with the universe of legal matters (Conte, 2014).

The mediation process in Albania is regulated by law no.10385, date 24.2.2011 "For Mediation in Dispute Resolution", amended by Law No.81/2013, date14.02.2013. This law is aligned with the directive 2008/52/EC "On some aspects of mediation in civil and commercial matters ", with nr. CELEX 32008I0052. In the Directive 2008/52 of The European Parliament and of The Council of 21 May 2008 on certain aspects of mediation in civil and commercial matters, at the 
article 10 is defined as "This Directive should apply to processes whereby two or more parties to a cross-border dispute attempt by themselves, on a voluntary basis, to reach an amicable agreement on the settlement of their dispute with the assistance of a mediator. It should apply in civil and commercial matters. However, it should not apply to rights and obligations on which the parties are not free to decide themselves under the relevant applicable law. Such rights and obligations are particularly frequent in family law and employment law (European Union, 2008). The law on the mediation process has an area of application in resolving all disputes in the field of civil, commercial, labor and family law. According to the definition of the law, mediation is defined as non-judicial activity in which the parties seek the settlement of a dispute by a third neutral person (mediator), qualifying as an independent solution to the dispute, it is sufficient for the agreement between the parties to be exercised in accordance with the law. By law, mediators have no right to order, or to force parties to accept the resolution of the dispute.

In the effort to define the mediation law, its use and its importance different author underline the necessity of the process of mediation and the benefits from its use for the parties that are involved in a conflict. This effort to "reorient the parties [to a dispute] to each other," and to facilitate the solving of problems and, in the best of all worlds, the making of peace, between couples, communities, companies or countries, requires an interdisciplinary orientation (Menkel-Meadow, 2016). Mediation law has many benefits but it is a difficult process to arrive until to the good understanding and compromise between parties, and in the entire process an important role play the skills of the mediator. We need human knowledge and understandings drawn from a variety of constituent fields - older ones like history, law, psychology, sociology, economics, political science and international relations, and newer ones, including decision sciences, game theory and urban planning (Menkel-Meadow, 2016), and this definition show the level of knowledge and about the difficulties and complications that the mediator face in the mediation process. The mediation process, in its deepest meaning, can be presented as a search for a process, or for a "shared culture" of conflict resolution, which at its end determines the nature of the outcome of the conflict and the solution to it (Alberstein, 2014).

\section{Methodology}

This paper has been constructed with the interplay of several study methods such as observation, research, analysis and synthesis. The work comes as a result of long-time observation, while working as an intermediate, and especially from the results achieved in the television program "See in the Court" broadcast on one of the national televisions in Albania. This practice has contributed to the clarification of the functioning of the concrete effects of all that is expressed in theory for mediation but also for further exploration in this field. In addition, the paper pays attention to the studies and treatments of various authors, who have focused attention on the mediation process, mediatisation of mediation process, and its effects. The research results of the studies and publications, as well as the results achieved by the mediation process from the television program transmitted to the national television, as well as the response monitoring in the social networks for each of the cases treated in the program, are analyzed and synced for bring it together in the form of the article.

\section{Media and Mediation Law}

The model of humanistic mediation, as developed by Umbreit in his book "Humanistic Mediation: $A$ Transformative Journey of Peacemaking, 14 MEDIATION Q. 201", published in 1997, and the victim-offender mediation inspired by ideas of "restorative justice" (Zehr, 1990), can both be located within this stage of critique of liberalism and in its appeal to community and relationship (Alberstein, 2014). Several essays also investigate how the interpersonal nature of a relationship between people determines the method selected to handle disputes, the impact of the "lens of gender" on our thinking about negotiation as a social activity for problem solving, and the tension between selfinterest and fairness in negotiation and the use of justifications and impression management to resolve this tension (Gleason, 1997). The time that individuals are devoting to information and 
information technology, as well as the services they provide, is growing. The period we live rightly is called the era of information technology. Due to the importance and power not only of public information, the media is rightly called the fourth power. The process underlying media influence can be broadly decomposed into two potential effects: (1) an individual or direct effect, and (2) a social or indirect effect. In the former, media provides information about new norms and persuades individuals to accept them (DellaVigna,S.; Gentzkow,M., 2010), (Bandura, 1986), (Arias, 2016). Mediation has a relational dimension that should be emphasized and promoted (Alberstein, 2014, p. 330).

In legal framework, Albanian society faces numerous problems, the origins of which, as well as their consequences, are multidimensional. The mediation process is a relatively new process in legal development in Albania. Nevertheless, the process of mediation today is increasingly taking on an important role, and among the reasons for the increase of mediation application, the role of the media is evidenced. The media handling of the mediation process has brought about a dynamic development of the process itself, its application, influencing the individuals involved in the conflict to reach an agreement, and then addressing their case to the court. People facing the prospect of litigation often wonder if their case is appropriate for mediation. However, when settlement is at least a remote possibility, mediation can bring the parties together and get the deal done (mediation-definition, 1995).

The implications of the meditation of the inter-mediation process are numerous, where we would highlight those that have influenced the numerical growth of the mediation application, the resolution of conflict between the parties, and the achievement of the agreement.

- First is breaking the taboos of dealing with a conflict. To share personal relationships with others is difficult for each of us and moreover, their treatment in the media poses a challenge to themselves and to the mentality of society. The mediation process for the nature as it develops requires an initial stage of conflict presentation. In the mediation process, it is necessary for the parties to express, for their claims, to discuss and debate until the agreement is reached, and of course, throughout this path, from the beginning to the end of mediation, it takes a long time to discuss, which, in a few cases, is difficult to manage. Given the fact that people in conflict have emotional burdens, the language used in discussion or debate raises difficulties in keeping the parties in a calm process. In a society where mentality and customary law seem to rule the legal right, there are always difficulties for the parties involved in the conflict, for the public treatment of conflict issues, which, for their resolution, have the necessity of reaching mediation between the parties .

- Secondly, it is information that is distributed to citizens. In a mediation process, there is indeed a conflict between the two parties, but the type of conflict, the genesis of conflict, interpretation of court decision, analysis of attorneys' actions, etc; therefore the treatment in the cause-and-effect context may be similar to many others who, until that moment due to lack of information, have thought of losing their cause. The media handling of different types of conflicts provides enough information, where many citizens receive indices to restore their cause, initially through the mediation process, and then running to the court, through the concept they have created for the interpretations and the law arguments, on how they should seek their right to the court.

- Third, dealing with conflict media, removes emotional barriers between the parties in conflict, and leads them towards resolution. But in addition, this also has an impact on social relations in society, since similar cases, many other parties in the conflict, start reflecting on forgetting the personal conflict by returning to a common request to find legal solutions to the genesis of the conflict, which at the beginning was legal and then, has also turned into personal conflict.

Mediators are said to act as neutral third parties who "empower" disputants to negotiate their own mutually acceptable agreement (G. Shailo, 1994).

\section{Conclusions}

Mediation is a delicate process whereby the mediator should manage the entire process very 
carefully. Mediation has a great role to play in alleviating and eliminating social conflicts, until the winning of the cause in the court. Media handling of the mediation process has multiple impacts. Publicly speaking in the visual media of conflict cases, apart from the dissemination of legal culture information, there are also important social implications, as each case incident promotes individuals to go to the mediation path for the various conflicts they carry.

The social effects already created as a cause of media handling of conflicts are evident, and this is evidenced by the parties' own demand for the mediation process, but also the parties do not hesitate to treat their conflict in public/media. Despite the fact that in the media it is a personal conflict between the two parties, the mediation process between parties is transformed into a public interest, because of the similarity of the case for many others, so this reflect as encourage to other individuals to break down personal and emotional barriers, moving towards conflict resolution through mediation.

\section{References}

Alberstein, M. (2014, January 1). The Ohio State University- University Libraries. Retrieved May 15, 2017, from https://kb.osu.edu/dspace/: https://kb.osu.edu/dspace/bitstream/handle/1811/77124/OSJDR_V22N2_0321.pdf?sequence=1

Arias, E. (2016, Aprile 27). How Does Media Influence Social Norms?A Field Experiment on the Role of Common Knowledge*. Retrieved December 15, 2017, from New York University.: https://as.nyu.edu/content/dam/nyu-as/politics/documents/AriasCommonKnowledge.pdf

Bandura, A. (1986). Social Foundations of Thought and Action: A Social Cognitive Theory. Englewood Cliffs, NJ, US: Prentice-Hall.

Conte, G. (2014). The Italian Way of Mediation. Arbitration Law Review , Volume 6 Yearbook on Arbitration and Mediation, .

DellaVigna,S.; Gentzkow,M. (2010). "Persuasion: Empirical Evidence.". Anual Review of Economics, Vol. 2: 643-669.

European Union, D. 2. (2008, May 24). Directive 2008/52/EC of the European Parliament and of the council, of 21 May 2008, on certain aspects of mediation in civil and commercial matters. Retrieved May 24, 2008, from Official Journal of the European Union,: http://eur-lex.europa.eu/legalcontent/EN/TXT/PDF/?uri=CELEX:32008L0052\&from=EN

G. Shailo, J. (1994). Empowerment in Dispute Mediation: A Critical Analysis of Communication. Westport, CT: Praeger Publishers.

Gleason, S. E. (1997). Workplace Dispute Resolution: Directions for the 21st Century. Michigan: Michigan State University Press.

mediation-definition. (1995, Janauary 1). Retrieved January 11, 2018, from Hg.org: https://www.hg.org/mediation-definition.html

Menkel-Meadow, C. (2016, February 9). Univrsity of Carolina, Irvine. Retrieved February 16, 2016, from http://www.law.uci.edu: http://www.law.uci.edu/faculty/full-time/menkel-meadow/mediation-applicationsfor-good-decisionmaking-Acta-KULeuven.pdf

Spencer, D., Brogan, M. (2006). Mediation Law and Practice. New York: Cambridge University Press.

Zehr, H. (1990). Changing lenses: A new focus to crime and justice. Virginia Avenue Harrisonburg: Herald Press 